\author{
JORGE ALBERTO MANRIQUE \\ INSTITUTO DE INVESTIGACIONES ESTÉTICAS, UNAM
}

\title{
Edmundo O'Gorman, 1906-1995
}

$\mathrm{E}$ Dmundo O'Gorman fue sin duda uno de los pensadores más lúcidos de México en filosofía de la historia. Realizó algunas de sus aportaciones mayores en el campo de la teoría histórica, y la influencia de su pensamiento produjo - no sin atravesar aguerridas polémicas - cambios sustanciales en la práctica de la historia.

El corpus de su pensamiento acerca del quehacer en la historia apareció entre 1942 y 1958 - aunque tuvo antecedentes importantes, como el primer prólogo a la edición, en 1940, de la Historia natural de la Indias, de Joseph de Acosta- En el primer año apareció Fundamentos de la historia de América, que es el primer acercamiento consistente a la cuestión americana y, simultáneamente, su primera aportación histórica sólida; de 1947 es Crisis y porvenir de la ciencia histórica, su libro más estrictamente teórico, casi con un sentido de manifiesto, y 1951 vio La idea del descubrimiento de América - que produjo un intercambio epistolar de gran altura con el historiador francés Marcel Batallion-, el cual tendría su culminación lógica sobre la disputa de América y su pensamiento teórico en La invención de América, de 1958 (y la edición aumentada de éste en inglés, en 196I).

El historicismo de O'Gorman se conforma a partir de posturas filosóficas coetáneas, como las de José Ortega y Gasset, José Gaos y Martin Heidegger; retoma temas de la filosofía de la Ilustración y el idealismo alemán, así como de Gian Battista Vico, y se nutre de su amplísimo conocimiento de la filosofía en general y de los historiadores desde la antigüedad (no olvidemos que fundó y atendió por muchos años la cátedra de historia de la historiografía en la Facultad de Filosofía y Letras). Cobra su sentido al asentar que 


\section{6}

no hay legítima tarea histórica que no se plantee y realice —en la práctica misma de historiar - una reflexión sobre los propios fundamentos de ese quehacer.

Se trata de una reflexión que se lleva adelante a partir del mayor rigor en la investigación, pero que tiene por premisa reconocer que la interpretación de los hechos - y no hay hechos que no sean, por fuerza, interpretacioneses también un proceso histórico, dependiente del sujeto que la hace y de su momento y circunstancia. En fin, hacer historia es un modo de tomar conciencia, de comprometernos, y en última instancia de manifestarnos, dejando testimonio de nosotros mismos.

La posición de O'Gorman puso en crisis la historia tradicional positivista y toda historia cientificista que proponga verdades absolutas. Abrió, así, la posibilidad de una nueva historia, más modesta en sus pretensiones de verdad (pero no por ello menos rigurosa) y al mismo tiempo más consciente y más altiva en su condición de rica expresión humana.

Frente a sus detractores, que lo tachaban de "filósofo, no historiador", O'Gorman respondió con prolijos trabajos históricos, entre ellos las ediciones anotadas, comentadas y prologadas de muchos de los clásicos de la historia (Acosta, Sierra, Mier, Las Casas, Anglería, Motolinia, Alva Ixtlixóchitl). En sus trabajos, que son historia strictu sensu, aparecen siempre las preocupaciones fundamentales que dan lugar a las interpretaciones y enriquecen notablemente las conclusiones.

Edmundo O'Gorman tuvo una formación inicial de abogado y practicó esa profesión por diez años desde su salida de la Escuela Libre de Derecho. A partir de 1938 dejó la abogacía y entró como subdirector al Archivo General de la Nación. Simultáneamente ingresó a la Facultad de Filosofía y Letras y se dedicó ya en forma exclusiva a la historia. Fue profesor de la Facultad de Filosofia y Letras, miembro honorario del Instituto de Investigaciones Estéticas, miembro del Instituto de Investigaciones Históricas, consejero del Centro de Estudios de Historia de México Condumex y profesor de la Universidad Iberoamericana.

Fue miembro de número de la Academia Mexicana de la Historia, y su director por varios periodos, así como miembro de número de la Academia Mexicana (de la lengua). Recibió diversas distinciones, como profesor emérito de la Universidad Nacional Autónoma de México, el doctorado Honoris causa por ésta misma, el Premio Americano Rafael Heliodoro Valle y el Premio Nacional de Ciencias y Artes. 
DOI: http://dx.doi.org/10.22201/iie.18703062e.1995.67.1750

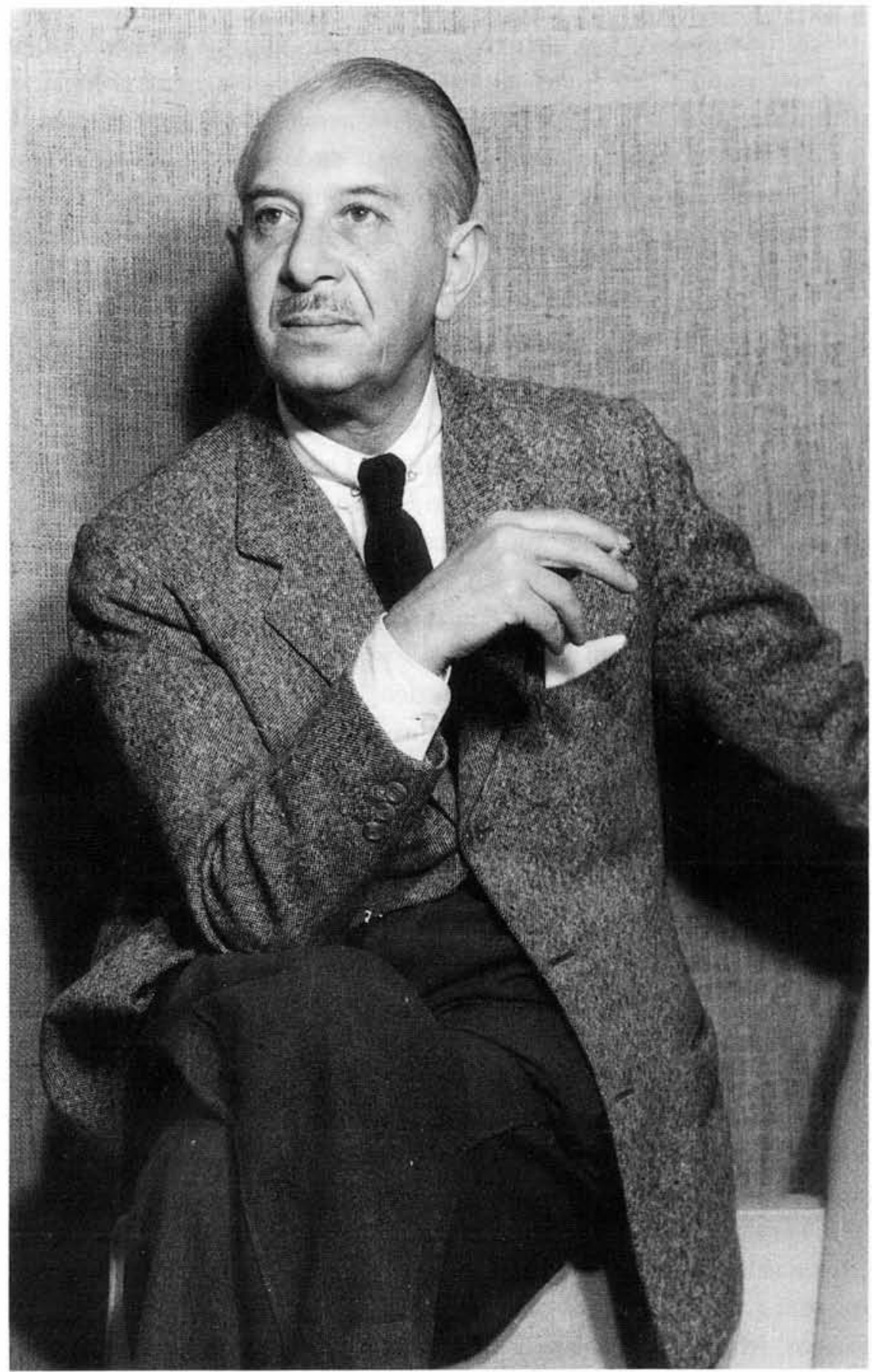

Edmundo O'Gorman, circa 1959-1960. Foto: Elisa Vargaslugo, Archivo Fotográfico Manuel Toussaint, Instituto de Investigaciones Estéticas, UNAM (en adelante IIE). 
Nació Edmundo O'Gorman en Coyoacán; de niño fue llevado a Guanajuato y regresado a San Ángel, donde de hecho residiría hasta el fin de sus días. Era hijo de dos ramas de la familia O'Gorman, de origen irlandés, una llegada al asunto de las minas poco después de la independencia y la otra venida con el mismo objeto 75 años después. Su padre, don Cecil, tenía un interés muy sólido por las letras, la historia y el arte; él mismo fue un fino pintor. Su hermano Juan tiene un sitio importante en la cultura mexicana como arquitecto y pintor.

En ese ambiente familiar O'Gorman tuvo desde temprano una relación amistosa con historiadores e historiadores del arte, especialmente con Manuel Toussaint, fundador del Laboratorio de Arte de la Universidad (luego Instituto de Investigaciones Estéticas). Desde la adolescencia mantuvo un lazo de estrecha amistad con Justino Fernández, que más tarde sería figura muy destacada entre los historiadores del arte y dirigiría el instituto. Igualmente fue muy cercano a Francisco de la Maza y a prácticamente todos los miembros de nuestra institución. Colaboró en varios trabajos de historia del arte prohijados por el Instituto de Investigaciones Estéticas, especialmente sobre los orígenes de la litografía en México.

Fue nombrado por la comunidad de investigadores miembro honorario del instituto, y como tal apareció, invariablemente, en estos Anales. Asimismo, por mucho tiempo formó parte de su Comisión Dictaminadora, con la que tuvo la responsabilidad de los concursos y promociones del personal académico. Fue un participante entusiasta de los coloquios internacionales y otras reuniones académicas organizadas por nosotros. En más de una ocasión aceptó la tarea de relator general, como en el primer coloquio, realizado en Zacatecas en 1975.

Fue amigo de muchos artistas (conservaba una obra que le regalara José Clemente Orozco) y él mismo, por temporadas, practicó la pintura, primero haciendo "glosas" de artistas contemporáneos y luego realizando una obra más personal, posmoderna ante litteram, con ecos de la pintura novohispana y de la pintura holandesa. También fue apasionado arquitecto "por la libre", especialmente en sus muy interesantes casas de Temixco.

En 1940 había escrito O'Gorman un artículo seminal, "El arte o de la monstruosidad", donde planteaba la necesidad de emplear categorías diferentes para acercarnos a esos objetos del mundo prehispánico que llamamos artísticos. Mucho más tarde, a propósito de una exposición de Antonio Peláez en el Palacio de Bellas Artes, escribió otto ensayo que proponía interpretaciones sobre la condición del arte llamado abstracto. 
DOI: http://dx.doi.org/10.22201/iie.18703062e.1995.67.1750

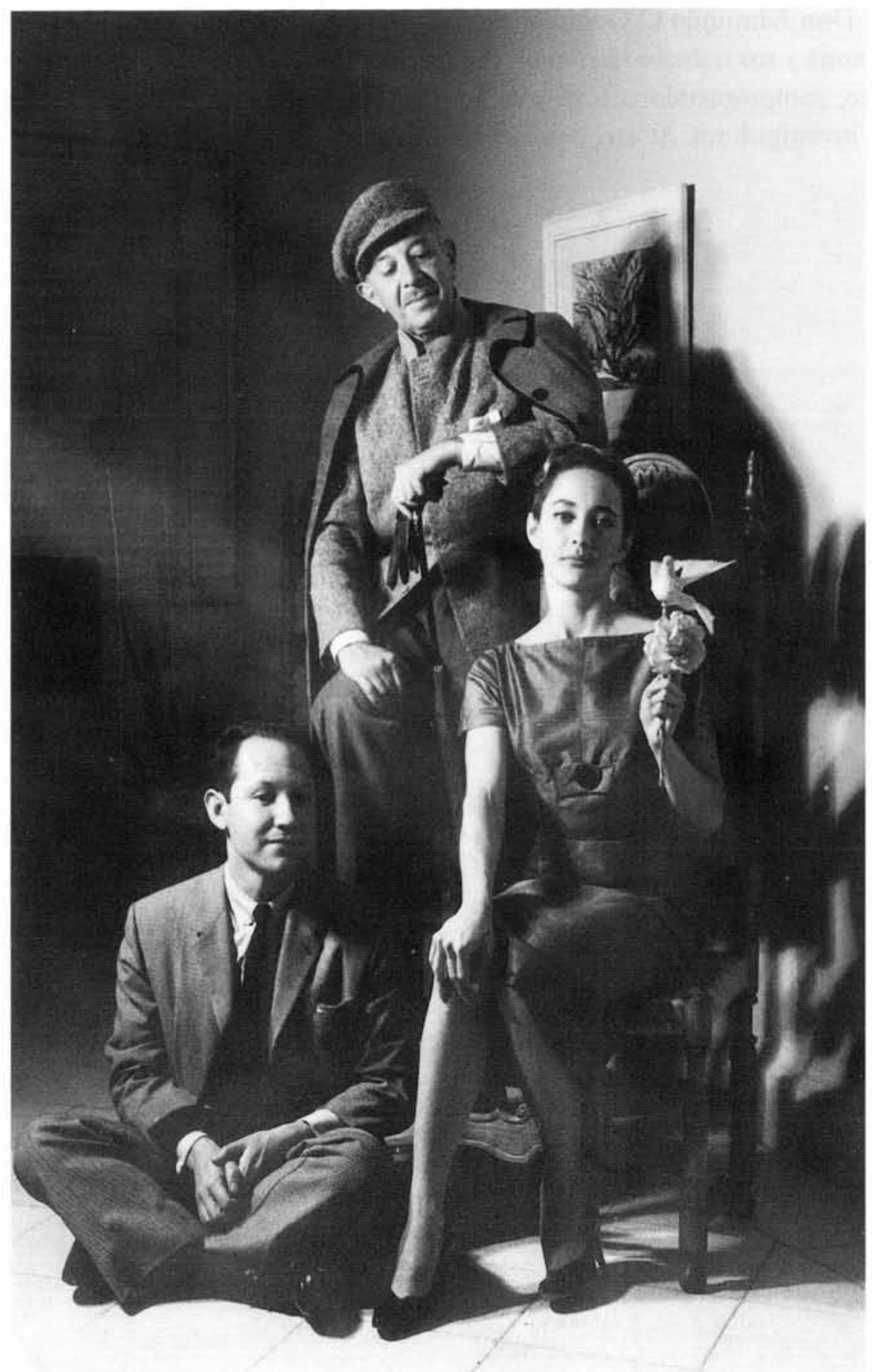

Sergio Fernández, Edmundo O'Gorman y Gloria Cándamo, circa 1959-1960. Foto: IIE. 
DOI: http://dx.doi.org/10.22201/iie.18703062e.1995.67.1750

200

JORGE ALBERTO MANRIQUE

Don Edmundo O'Gorman, además de sus aportaciones en la teoría de la historia y sus trabajos históricos, fue un miembro destacado de nuestro instituto, comprometido con su vida académica y amigo de varias generaciones de investigadores. $\mathrm{Al}$ irse, perdemos un amigo y un apoyo invaluable. $\$$ 